\title{
Non-destructive Micro-structural Characterization of Metallic Specimens with a Portable X-ray Diffraction based Residual Stress Analyzer
}

\author{
P. Ganesh ${ }^{1}$, D. C. Nagpure ${ }^{1}$, Rakesh Kaul ${ }^{1}$, R. K. Gupta ${ }^{1}$, L. M. Kukreja ${ }^{1}$ \\ ${ }^{1}$ Laser Materials Processing Division, Raja Ramanna Centre for Advanced Technology, P.O.: CAT, Indore 452013, \\ India \\ Correspondence: P. Ganesh, Laser Materials Processing Division, Raja Ramanna Centre for Advanced Technology, \\ P.O.: CAT, Indore 452013, Tel: +91 731 2488381; Fax: +91 731 2488380, India
}

Received: March 23, 2015

Accepted: April 14, $2015 \quad$ Online Published: April 27, 2015

doi:10.11114/set.v2i1.795

URL: http://dx.doi.org/10.11114/set.v2i1.795

\begin{abstract}
Non-destructive characterization of surface microstructure of an engineering component is an important parameter to assess its fitness to function in the given service conditions. The paper describes various case studies performed in authors' laboratory involving use of portable X-ray diffraction based residual stress analysis system to examine and understand the micro-structural state of the investigated surface. A significant decrease in full width at half maximum (FWHM) of gamma(311) diffraction peak from about $4.2^{\circ}$ in the cold worked state to about $2.5^{\circ}$ in the annealed/surface melted state was recorded for austenitic stainless steel. In case of $0.4 \%$ carbon steel there is sharp increase in FWHM of alpha(211) diffraction peak from about $2^{\circ}$ in the as received condition to about $5-6^{\circ}$ in the laser hardened condition. Crystallographic texture developed during electro-plating of chromium on stainless steel, could be detected from the strong intensity of alpha (211) peak of chromium at about $19^{\circ}$ to the surface normal with respect to all other X-ray inclination angles $(\psi)$ during residual stress measurement. The results show that FWHM and intensity variation of the diffraction peak are two sensitive parameters for characterization of surface microstructure. Change in FWHM has been used to detect machining-induced cold deformation and evolution of re-crystallized grains in austenitic stainless steel and formation of hard martensite in laser transformation hardened ferritic steel. Variation in the intensity of diffracted peak with respect to X-ray inclination angle provided valuable information regarding crystallographic texture in hard chrome plated deposits.
\end{abstract}

Keywords: X-ray diffraction, microstructure, stress measurement, full width at half maximum, texture

\section{Introduction}

Surface microstructure of a component plays an important role in governing response of an engineering component against various surface degradation mechanisms, including corrosion, wear, stress-corrosion cracking, fatigue, corrosion-fatigue, hydrogen embrittlement etc (Yamashita et al., 1997, Koul et al., 1988, Ghosh et al., 2010, Ghosh et al., 2011, Etienne et al., 2010, Mandal et al., 2007, Liu et al., 1992. The procedure adopted for fabrication of a component (involving machining, welding and heat treatment) as well as its service conditions (stress, temperature, ambiance etc. greatly influence its surface microstructure (Yamashita et al., 1997, Koul et al., 1988, Ghosh et al., 2010, Ghosh et al., 2011). Therefore, non-destructive characterization of surface microstructure of as-fabricated and in-service components is very important parameter to assess their suitability to function and residual life in a given service environment (Dobmann et al., 1997, Sagar et al., 2005, Nanekar et al., 2004, Frank et al., 2000, Mathew et al., 2010, Rai et al., 2004, et al., Rai et al., 1999). In this respect, there are situations demanding even in-situ micro-structural analysis. Conventional metallographic technique, because of its inherent limitation of being destructive in nature, cannot be applied on actual engineering components. In-situ metallographic technique, although very effective, does not provide complete micro-structural and related information, including phase identification, surface deformation, texture and state of stress. On the other hand, X-ray diffraction, due to its versatile nature, is an effective non-contact technique for analysis of surface microstructure, texture and state of stress (Frank et al., 2000, Rai et al., 2004, Rai et al., 1999, Snyder et al., 1999, Vivek et al., 2013). However, conventional X-ray diffractometer, does not permit analysis of large and odd shape components. In this respect, a compact X-ray diffraction based residual stress analysis system, due to its portability and ability to extract micro-structural information from localized regions of large size or even odd-shaped components, is an effective tool for performing in-situ micro-structural analysis on engineering components which 
cannot be examined by a conventional X-ray diffractometer. In spite of its associated limitations with respect to short range of diffraction angles, the instrument provides useful information on surface microstructure, texture and state of stress with spatial resolution depending upon the size of the aperture chosen and distance between successive stress measurement locations. The versatility of the instrument can be further augmented by using it in conjunction with a portable electro-polisher which can remove the surface layer from the intended location in a controlled manner in steps of about $20-40 \mu \mathrm{m}$ up to the desired depth for obtaining stress measurements. The combined system can effectively function as a semi-destructive technique for extracting sub-surface microstructural information as well. The forthcoming part of the paper describes few case studies performed in authors' laboratory using a portable X-ray based stress analyzer.

\section{Experimental}

Various case studies, presented in the forthcoming part of the paper, have been performed using a Proto make portable $\mathrm{X}$-ray diffraction based stress measurement system (Model iXRD). The system is equipped with replaceable miniature $\mathrm{X}$-ray tubes of different wavelengths (Target materials: $\mathrm{Cu}, \mathrm{Cr}, \mathrm{Mn}$ and $\mathrm{V}$ ) and power supply rating of maximum 30 $\mathrm{kV}-6.7 \mathrm{~mA}$. The diffracted X-ray radiation is picked by two symmetrically placed (with respect to incident X-ray beam) position sensitive scintillation detectors (PSSD). Figure 1 shows the configuration of X-ray source and the detectors. Det1 and Det2 stand for two detectors (PSSD) mounted on an arc shaped goniometer, with an angular range of 18 degrees each (figure 1a). The range of diffraction angle (2O) covered by the goniometer of the stress analyzer is $120-$ 160 degrees. The procedure of stress measurements involves recording profile of a diffraction peak (for a given crystallographic plane) at different inclination angles $\psi$ (angle between associated crystallographic plane (hkl) and specimen surface normal) with inter planar spacing "d" (refer figure 1b). Using the resultant $d-\operatorname{Sin}^{2} \psi$ plot, the magnitude of surface residual stress in the given direction is estimated (Cullity 1978, Noyan \& Cohen, 1987). The investigated spot on surface of the specimen is controlled by using apertures of different sizes. The system relies on using appropriate characteristic radiation (obtained by using different replaceable miniature X-ray tubes) to obtain diffraction peak in the detectable $2 \Theta$ range of the diffractometer. It should be noted that apart from providing magnitude of residual stress, the stress analysis system also provides position (2Ө), width (full width at half maximum) and intensity of given diffraction peak at different $\psi$ inclinations. While shift in peak position with respect to inter-planar spacing of chosen atomic plane is employed for estimating magnitude of residual stress, the other two parameters viz. width and intensity of diffraction peak can provide useful micro-structural information related to investigated surface. While width of diffraction peak is governed by associated grain size and deformation, the distribution of intensity of a given diffraction peak at different $\psi$ inclination angles provides information about associated crystallographic texture. Experimental parameters of the various case studies are discussed in detail in the each case study as they differ form case to case depending on ef material under investigation.

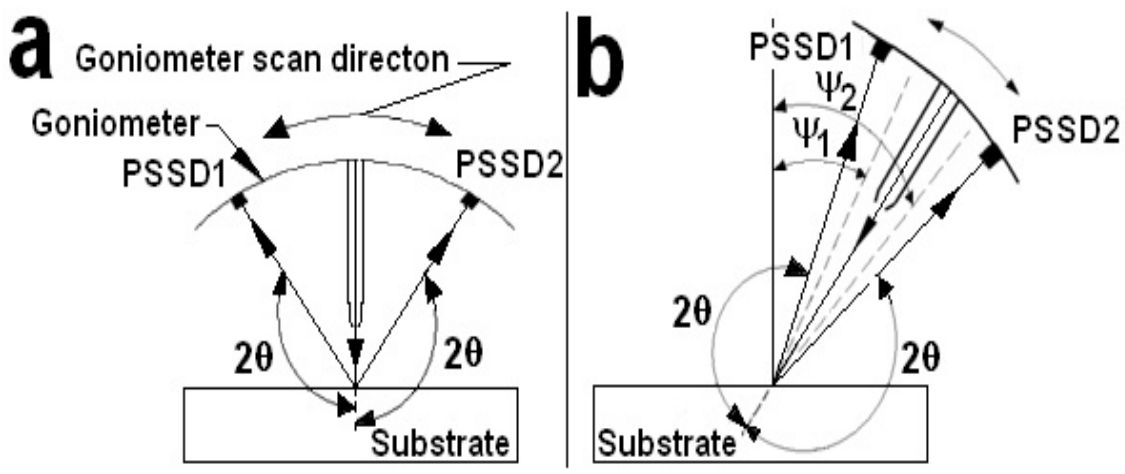

Figure 1. Schematic illustration of (a) goniometer head of residual stress analyzer and (b) inclination angle, $\psi$ for the two position sensitive scintillation detectors PSSD1 and PSSD2

\section{Case Studies}

\subsection{Detection of Surface Deformation and Annealing Effects in Austenitic Stainless Steel}

Surface deformation and annealing effects in austenitic stainless steel were analyzed with MnK $\alpha$ characteristic radiation (wave length $(\lambda)=2.10 \AA$ ). Residual stress measurement involved recording of austenite $(\gamma)$ (311) diffraction peak at $2 \Theta=152^{\circ}$ in two orthogonal directions (circumferential and longitudinal) at eleven different $\psi$ inclinations, in the range of $-44^{\circ}$ to $+44^{\circ}$. A circular spot of $2 \mathrm{~mm}$ diameter was selected for the said examination. Both surface and depth profiling modes were employed to obtain desired surface and sub-surface micro-structural information. Depth profiling of residual stress involved sequential electro-polishing and stress measurement at regular intervals of about $50 \mu \mathrm{m}$. 


\subsubsection{Machining-induced Cold Deformation in Type 304 Stainless Steel}

Machining forms an important part in the fabrication of an engineering component. The process of machining involves, large amount of in-homogeneous plastic deformation, along with heat generated during machining, leaves a modified surface layer on the machined component. Possible types of surface damage introduced by machining are: (i) increase in surface roughness - deeper and sharper machining grooves may act as stress raisers, (ii) strain hardening with higher dislocation density, (iii) phase transformation with associated change in volume and (iv) high magnitude of tensile residual stresses - algebraically added to applied stresses during service. The nature of the modified surface layer is an important factor governing component's performance with respect to corrosion, wear and fatigue etc. (Ghosh et al., 2010, Ghosh et al., 2011, Ganesh et al., 2014).

In the present case study, aimed to examine the micro-structural modifications on the surface of a machined component, a $37.7 \mathrm{~mm}$ diameter rod of AISI 304 stainless steel was machined (turning) using a lathe machine. Surface roughness of as-machined surface was $0.62-1.1 \mu \mathrm{m}$. The results of the stress analysis carried out on the machined surface in two orthogonal directions (longitudinal and circumferential/hoop) revealed that as-machined surface of stainless steel rod carried high magnitude of tensile residual stresses. With respect to longitudinal direction, circumferential direction carried higher magnitude of tensile residual stress. The cutting force in the hoop direction is usually the largest and has the most significant effect on the residual stresses on a turned surface. Therefore, it is likely to expect the largest stress in the circumferential/hoop direction (Jang, Watkins, Kozaczek, Hubbard \& Cavin, 1996). Machining induced tensile residual stresses displayed sharp gradient in the shallow surface layer of $80 \mu \mathrm{m}$ depth in which residual stresses experienced rapid drop as shown in Figure 2a. In addition, $\gamma(311)$ diffraction peak also recorded considerably higher full width at half maximum (FWHM). Like residual stress, mean width (FWHM) of $\gamma(311)$ peak also exhibited sharp fall in the top $80 \mu \mathrm{m}$ thick surface layer. Figure $2 \mathrm{~b}$ presents depth profile of mean FWHM of $\gamma(311)$ diffraction peak in machined stainless steel rod. Higher width of austenite diffraction peak is caused by higher plastic deformation at the surface introduced by machining.
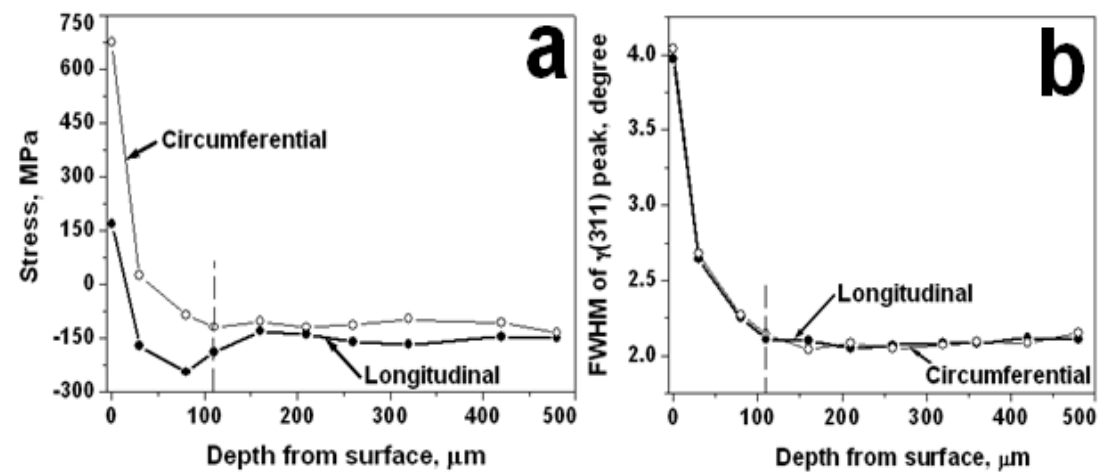

Figure 2. Depth profiles of (a) residual stresses and (b) FWHM of austenite (311) diffraction peak, as measured along circumferential and longitudinal directions in a machined rod of type 304 stainless steel.

\subsubsection{Elimination of Surface Deformation Effects through Laser Surface Melting of Type 304 Stainless Steel}

Recent research studies performed in authors' laboratory have demonstrated effectiveness of laser surface melting as a tool for micro-structural engineering for enhancing resistance of austenitic stainless steel against inter-granular corrosion (Kaul et al., 2008, Parvathavarthini et al., 2008, Kaul et al., 2009). Apart from effecting micro-structural modification, laser surface melting, also serves to completely eliminate cold deformation present on the surface of the component. In austenitic stainless steel, surface deformation adversely affects its corrosion characteristics (Ghosh et al., 2010, Ghosh et al., 2011, Subba Rao et al., 2007).

Experiments involving laser surface melting treatment were performed with a $100 \mathrm{~W}$ Nd:YAG laser (Gupta et al., 2015). It involved scanning surface of $5 \mathrm{~mm}$ thick machined plate of type 304L stainless steel substrate with a focused laser beam at a scan rate of $15 \mathrm{~mm} / \mathrm{s}$. Laser treatment yielded $50-60 \mu \mathrm{m}$ thick surface melted layer. Surface profile of $\gamma(311)$ diffraction peak of partly laser surface melted stainless steel specimen exhibited considerable reduction in FWHM in the surface melted region. Figure 3 shows the FWHM profile of $\gamma(311)$ diffraction peak from the measurements carried out on the surface of the partly surface melted 304L SS specimen in both regions viz. as-machined as well as in laser melted region over a length of about $40 \mathrm{~mm}$. The reduction in diffraction peak width (FWHM) is related to elimination of cold deformation effects present on the surface of as-machined stainless steel plate. 


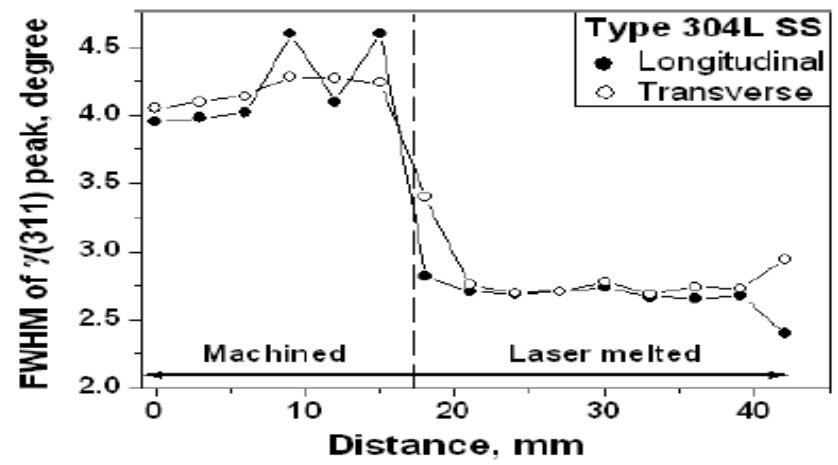

Figure 3. Profile of FWHM of austenite (311) diffraction peak, as measured by residual stress analyzer, along (longitudinal) and across (transverse) laser scanning direction on the surface of machined plate. Measurements were taken partly on the as-machined surface and partly on the laser melted regions of type 304L stainless steel.

\subsubsection{Re-crystallization of Cold Worked Type 304 Stainless Steel through Laser Surface Heating}

This case study is a part of surface modification experiments performed in authors' laboratory to achieve surface recrystallization in type 304 stainless steel for enhancing resistance against intergranular corrosion (Ganesh et al., 2013b). The approach adopted for surface modification included shot blasting followed by multi-pass laser surface heat treatment, performed with a continuous wave $(\mathrm{CW}) \mathrm{CO}_{2}$ laser beam. In this process, shot blasting was used to introduce large amount of cold deformation into the material while subsequent solid-state laser heating served to facilitate formation of fine re-crystallized grains.

The results of residual stress measurement revealed that severe plastic deformation and resultant breakdown of surface grains brought about significant increase in FWHM of austenite (311) diffraction peak. Initial part of laser surface treatment of shot blasted surface witnessed relaxation of compressive residual stress introduced by shot blasting, without any noticeable change in FWHM of diffraction peak. Rapid relaxation of compressive surface residual stress is indicative of recovery of highly cold worked microstructure introduced by shot blasting (Hosford, 2005). On the other hand, later stage of laser surface heat treatment brought about significant reduction in FWHM of diffraction peak, as shown in figure 4. Detailed results of this study along with stress variation data and microstructural variation due to laser treatment are discussed elsewhere (Ganesh et al., 2013b). During re-crystallization, cold worked microstructure containing deformed grains transforms to stress-free grains (Hosford, 2005). Metallographic examination of the specimen confirmed that narrowing of diffraction peak was associated with evolution of re-crystallized grains associated with elimination of cold work after adequate laser treatment.

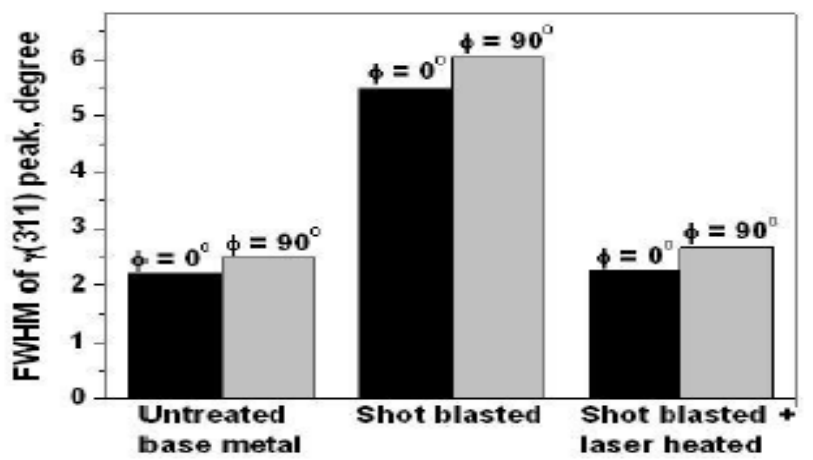

Figure 4. FWHM of austenite (311) diffraction peak of type 304 stainless steel in untreated, cold worked (through shot blasting) and re-crystallized (laser heating of cold worked specimen) conditions. $\Phi=0$ and 90 represent two orthogonal directions of stress measurements.

\subsection{Surface Micro-structural Analysis of Ferritic Steel Parts}

Surface microstructure of ferritic steel parts was analyzed with $\operatorname{CrK} \alpha$ characteristic radiation $(\lambda=2.29 \AA)$. Residual stress analysis of steel specimens involved recording of $\alpha(211)$ peak $\left(2 \Theta=156^{\circ}\right)$ at eleven different $\psi$ inclinations. Both surface and depth profiling modes were employed to extract desired micro-structural information.

\subsubsection{Surface Decarburization in Hardened and Tempered Plate of SAE 9260 Spring Steel}

Heat treatment of ferritic steel components in atmosphere usually results in surface decarburization which may bring about considerable reduction in surface hardness depending upon the extent of thermal exposure. This softened 
decarburized surface layer may facilitate early initiation of surface cracks during fatigue loading (Ganesh et al., 2012). The substrate used in this study was a $6 \mathrm{~mm}$ thick plate of SAE 9260 spring steel in hardened and tempered condition. The details of heat treatment were: hardening temperature $=895-935^{\circ} \mathrm{C}$ and tempering temperature $=450-490{ }^{\circ} \mathrm{C}$. The heat treated specimen exhibited tempered martensite microstructure with micro-hardness value of $440-480 \mathrm{HK}$ $($ load $=1.96 \mathrm{~N})$. Depth profiling of $\alpha(211)$ diffraction peak, on the substrate brought out considerable reduction in FWHM towards the surface, as shown in figure 5a. Metallographic examination of the heat treated specimens exhibited $50-100 \mu \mathrm{m}$ thick decarburized surface layer, as shown in figure. $5 \mathrm{~b}$. In the decarburized layer, the material suffered a drop in micro-hardness to $250-330 \mathrm{HK}(\mathrm{load}=1.96 \mathrm{~N})$. It should be noted that tetragonality of $\mathrm{Fe}-\mathrm{C}$ martensite (represented as c/a), increases with the carbon content (Reed-Hill, 1973). In X-ray diffraction, the tetragonality of martensite brings about fine splitting of martensite peak which usually appears in the form of a broadened peak (Cullity, 1978). About $125 \mu \mathrm{m}$ thick layer, associated with minimum peak width (FWHM) of 2.8 - 2.9, matches with metallographic observations and associated drop in micro-hardness from about $450 \mathrm{HK}$ in the bulk to about 250-300 HK in the decarburized region (Ganesh et al., 2014). This implies that surface decarburization brought about considerable reduction in tetragonality of ferrite phase and associated peak width. However, subsequent gradual rise of FWHM at depths beyond $100 \mu \mathrm{m}$ is believed to be related to enhanced tempering effects.

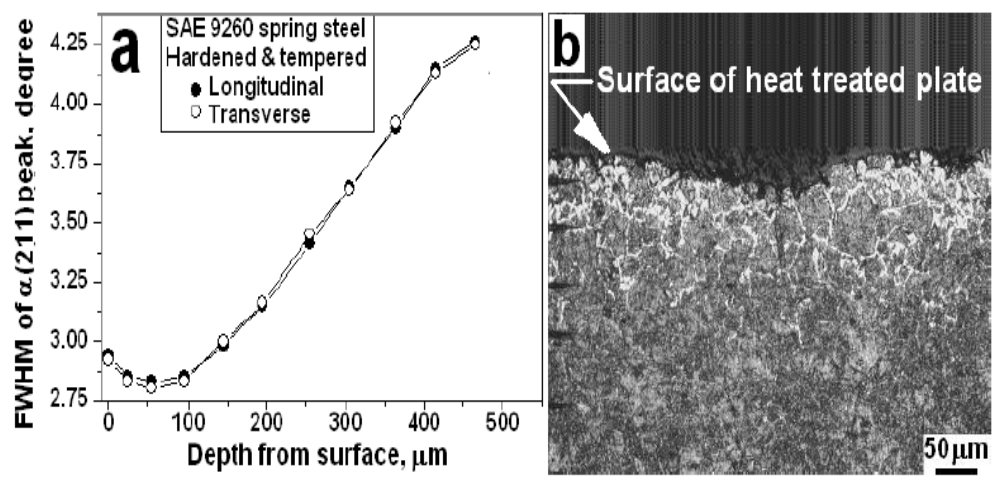

Figure 5. (a) Depth profile of FWHM of $\alpha$ (211) diffraction peak and (b) associated microstructure of the cross-section of hardened and tempered SAE 9260 spring steel specimen.

\subsubsection{Martensite Formation on Laser Treated Surface of AISI 1040 Steel}

Laser has found extensive application for transformation hardening of steel parts (Ion, J. C. 2002, Pashby et al., 2003, Kennedy et al., 2004). The technique is particularly suitable for localized surface hardening applications without the need for a separate quenching step. During the process of laser transformation hardening of steel parts, laser-exposed surface layer is briefly heated above upper critical temperature ( $\mathrm{Ac}_{3}$ for hypo-eutectoid steel)) to form austenite and subsequent to laser irradiation (as laser beam leaves the region) the surface layer is subjected to rapid cooling though self-quenching facilitating transformation of austenite into hard martensite (Deprez et al., 1990, Kaul et al., 2005, Dinesh Babu et al., 2013).

In the present case study, laser transformation hardening of AISI 1040 steel specimens $(30 \times 30 \times 5 \mathrm{~mm})$ was achieved by scanning surface of the steel specimens with an elliptical shaped (major axis: $11 \mathrm{~mm}$; minor axis: $1 \mathrm{~mm}$ ) $\mathrm{CW} \mathrm{CO}_{2}$ laser beam of $2.5 \mathrm{~kW}$ power at different speeds $(5-13 \mathrm{~mm} / \mathrm{s})$ (Ganesh et al., 2013a). In this study, residual stress analysis system was used to determine micro-structural state of laser treated surface and also (ii) determine total width of laser hardened zone and compare them with the corresponding information obtained by metallographic examination. Residual stress analysis, performed with $\mathrm{CrK} \alpha$ radiation $(\lambda=2.29 \AA)$, involved recording of $\alpha(211)$ peak $\left(2 \Theta=156^{\circ}\right)$ at eleven different $\psi$ inclinations.

A line-scan of residual stresses across laser-treated track, made with a scan rate of $13 \mathrm{~mm} / \mathrm{s}$, exhibited that with respect to untreated base metal, laser treated region developed higher magnitude of tensile residual stresses (up to $250 \mathrm{MPa}$ ). The increase in residual stress was not accompanied by any noticeable change in peak broadening of ferrite peak, as shown in figure 6a. Metallographic examination of transverse cross-section of laser treated specimen did not reveal any noticeable change in the microstructure (refer figure $6 \mathrm{~b}$ ). 


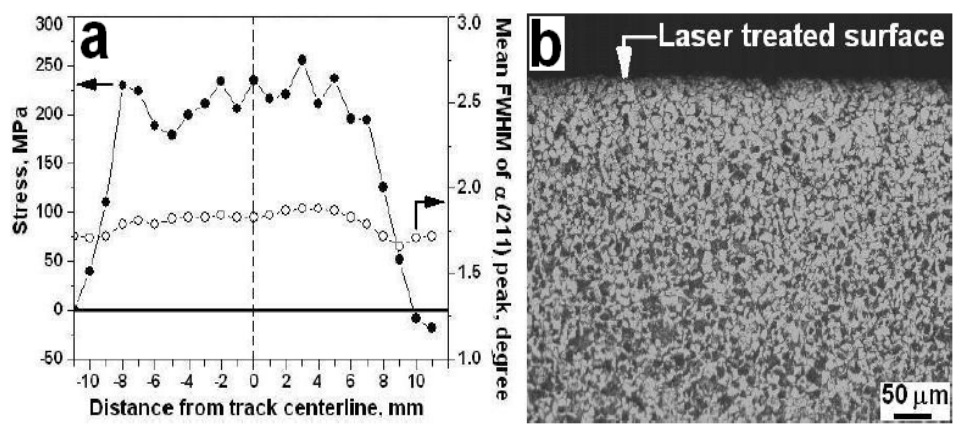

Figure 6. (a) Surface profiles of residual stress and FWHM of $\alpha(211)$ diffraction peak across laser treated track (laser power $=2.5 \mathrm{~kW}$ and scan rate $=13 \mathrm{~mm} / \mathrm{s}$ ) and (b) associated micro-structure of cross-section of AISI 1040 steel specimen.

Micro-hardness measurements carried out on the cross section of this specimen (load $=1.961 \mathrm{~N})$ also exhibited no change with respect to the hardness of the untreated substrate. The above results suggest that the maximum rise in surface temperature during laser surface treatment (at a scan rate of $13 \mathrm{~mm} / \mathrm{s}$ ) was below lower critical temperature $\mathrm{Ac}_{1}$ for the given steel to facilitate any phase transformation of room temperature micro-structure of ferrite and pearlite. However, local heating and cooling cycle experienced by the laser-irradiated region did result in modification in associated state of residual stress. During laser heating, laser irradiated zone tries to expand against colder surrounding regions. The resistance offered by surrounding regions against free expansion of laser irradiated region, puts this region under compression. During subsequent cooling, laser-irradiated region tries to shrink which is again resisted by surrounding regions, thereby resulting in generation of tensile stresses in this region. On the other hand, laser-treated track, made with a scan rate of $8 \mathrm{~mm} / \mathrm{s}$, displayed typical sine wave profile of residual stress across its width (figure 7a). Residual stress and peak broadening profiles displayed compressively stressed central zone of higher peak width, surrounded on its two sides by tensile stressed outer regions associated with lower peak width. The specimen treated with a scan rate of $8 \mathrm{~mm} / \mathrm{s}$ (due to relatively higher heat in-put), developed well transformed laser hardened zone (LHZ), without any sign of surface melting. Martensite formation along with volume expansion effects generated considerable increase in the width of ferrite peak and compressive residual stress in LHZ. Formation of uniform compressive stress and higher peak width at the center of the laser treated zone implies that, local peak temperature has reached above upper critical temperature $\left(\mathrm{Ac}_{3}\right)$ and resulted in complete dissolution of iron carbide and formation of austenite phase with carbon in solution during heating, which, upon self-quenching, transformed into high carbon martensite. Similarly, in the depth profiles, the region associated with compressive residual stress associated with broad ferrite peak (211) was regarded as the total depth of laser hardened zone.
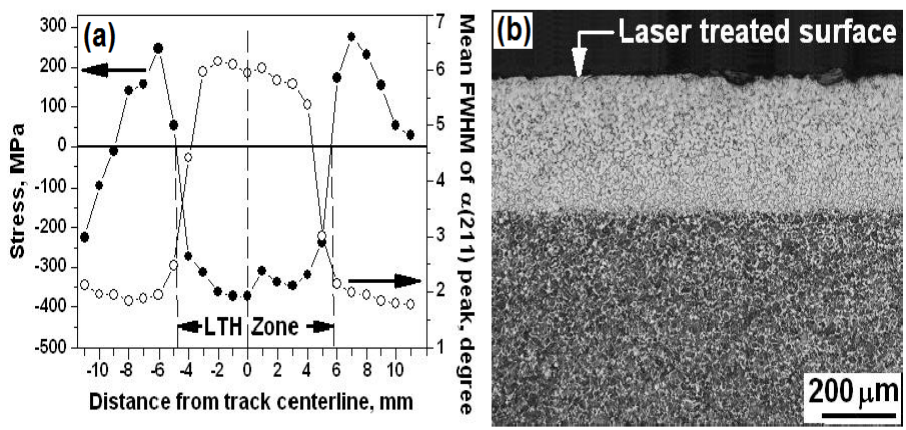

Figure 7. (a) Surface profiles of residual stress and FWHM of $\alpha$ (211) diffraction peak across laser treated track (power $=$

$2.5 \mathrm{~kW}$ and scan rate $=8 \mathrm{~mm} / \mathrm{s}$ ) and (b) associated micro-structure of cross-section of AISI 1040 steel specimen.

An important observation of residual stress and peak width of profiles across the laser treated zone was that the drop in peak width starts (as one moves away from the track centerline) before the onset of rise in residual stress. Cross-sectional metallographic examination of the specimen confirmed about $300 \mu \mathrm{m}$ deep laser transformation hardened layer, as shown in figure $7 \mathrm{~b}$. Micro-hardness measurements on the cross-section of laser hardened zone exhibited about 250-300 $\mu \mathrm{m}$ deep hardened zone with micro-hardness in the range of 500-650 HV (load: 200 gf) as compared to about $250 \mathrm{HV}$ for unaffected bulk. The micro-structure of laser hardened zone displayed steep micro-structural gradient ranging from homogenous lath martensite near the surface and in-homogenous martensite (in terms of its morphology) to dual phase martensite + pro-eutectoid ferrite microstructure at the bottom of laser hardened track. Similar micro-structural transitions were also recorded across the width of LHZ (Ganesh et al. 2013a). Table 1 summarizes dimensions of laser hardened zone (scanned with $8 \mathrm{~mm} / \mathrm{s}$ ), estimated based on results of residual stress and peak width profiles, along with actual measurements determined by metallographic examination. It is seen that 
estimated dimensions of laser hardened zone are quite close to the results of metallographic examination. As compared to residual stress, width of ferrite diffraction peak is a more sensitive parameter to estimate the extent of various micro-structural zones (laser transformation hardened zone) with different phase constitution. There is a steep rise in the FWHM of ferrite peak $(\alpha(211)$ diffraction peak) in the laser hardened region. This technique has a potential for in-situ micro-structural analysis of ferritic steel weldments. As compared to residual stress, width of ferrite diffraction peak is a more sensitive parameter to estimate the micro-structural changes involving change in tetragonality of martensite formation.

Table1.Width of laser transformation hardened (LTH) zone, as estimated by different approaches

\begin{tabular}{cccc}
\hline $\begin{array}{c}\text { Method of } \\
\text { measurement }\end{array}$ & $\begin{array}{c}\text { Variation in residual } \\
\text { stress }\end{array}$ & $\begin{array}{c}\text { Variation in peak width } \\
\text { (FWHM) }\end{array}$ & $\begin{array}{c}\text { Optical microscopy (microstructure } \\
\text { based) }\end{array}$ \\
\hline Width of LTH zone & $10.5 \mathrm{~mm}$ & $12 \mathrm{~mm}$ & $11 \mathrm{~mm}$ \\
\hline
\end{tabular}

3.3 Detection of Texture in Chromium Plating

Hard chromium electroplating, because of its high resistance against corrosion and wear, finds extensive applications in aerospace, automobile and petro-chemical fields. An important characteristic of chromium electroplated deposits is high magnitude of tensile residual stresses, which increase with the thickness of the deposit (Jones 1989, Dubpernell \& Lowenheim 1968, Kuo \& Wu, 1996). These stresses are relieved by local micro-cracking during the process of electroplating (Kuo \& Wu 1996, Nascimento et al., 2001). High tensile residual stresses and large density of micro-cracks present in the electroplated deposits are responsible for reduction in its fatigue strength (Nascimento et al., 2001). Hard chrome electroplated coatings deposited by direct current (DC) reportedly possess strong crystallographic texture ( $\{111\}$ fiber texture) that increases in the core of the coating with the growth in the thickness (Pina, 1997).

The present case study is part of a larger study aimed at enhancing fatigue life of hard chrome plated specimens of 15-5PH SS. The specimen used for the study was ground disc-shaped specimens (diameter: $50 \mathrm{~mm}$; thickness: $3 \mathrm{~mm}$ ) of 15-5 PH stainless steel in $\mathrm{H} 1025$ temper condition (solution treated at $1038{ }^{\circ} \mathrm{C}$ and aged at $551{ }^{\circ} \mathrm{C}$ ). The specimens were subjected to hard chrome plating. Cross-sectional examination of chrome plated specimen displayed about $210 \mu \mathrm{m}$ thick layer of chrome plating which was associated with short cracks mostly aligned along the thickness of coating. Figure 8 presents photomicrographs showing cracks on the surface and cross-section of chrome plated stainless steel specimen. In order to analyze micro-structural characteristics of chrome plated layer, the surface of chrome plated stainless steel specimens were subjected to residual stress analysis. In addition, the specimens were also subjected to depth profiling of residual stress as described above. Specimens' characterization was performed with $\mathrm{CrK \alpha}$ characteristic radiation $(\lambda=2.29 \AA)$ while using a circular spot of $2 \mathrm{~mm}$ diameter. Residual stress measurement involved recording of $\alpha(211)$ diffraction peak $\left(2 \Theta=156^{\circ}\right)$ in two orthogonal directions on the electroplated surface at 11 different $\psi$-inclinations, in the range of $-44^{\circ}$ to $+44^{\circ}$.

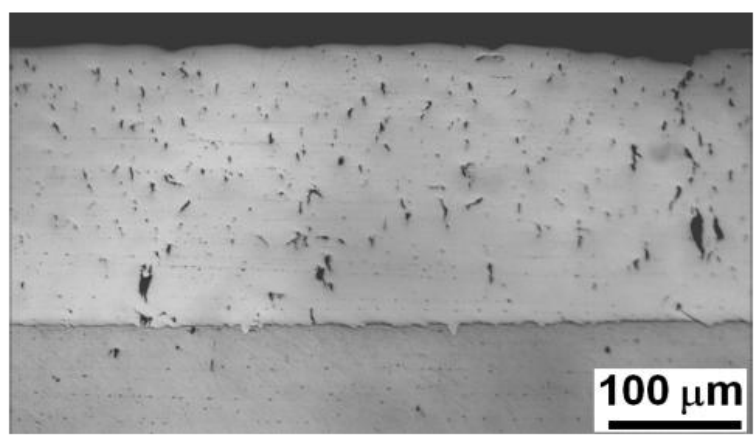

Figure 8. Cross-section of chrome-plated 15-5 PH stainless steel. Note numerous micro-cracks in the chrome plated layer at the top.

An important output of the results was large change in the intensity of $\alpha$ (211) diffraction peak with inclination angle. Repeated measurements at a number of sites on chrome plated surface revealed that at all the sites the maximum intensity of diffracted peak was recorded at an ( $\psi$-inclination angle of about $19^{\circ}$ with the surface. Figure 9 presents recorded profiles of the (211) diffraction peak at different $\psi$ inclination angles. 

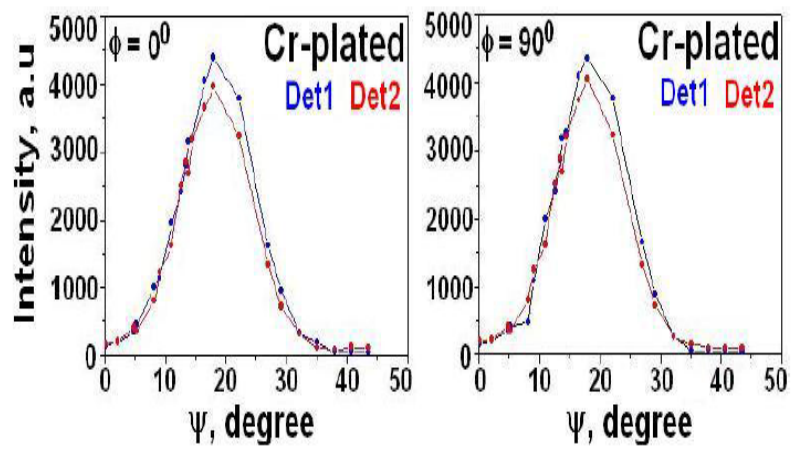

Figure 9. Variation of intensity of $\mathrm{Cr}$ (211) diffraction peak from chrome plated surface with respect to inclination angle $\psi$. Det1 and Det2 stand for two detectors (PSSD) placed on either side of the incident X-ray beam.

The results suggest that, on the chrome plated surface, maximum number of $\alpha(211)$ crystallographic planes are oriented at an angle of about $19^{\circ}$ (with respect to the surface). It should be noted that angle between the crystallographic planes (211) and (111) works out to be $19.46^{\circ}$, which is quite close to orientation of (211) planes with respect to chrome plated surface. The results therefore demonstrate that surface of chrome plated specimen carried strong $\{111\}$ texture which is in line with the reported results (Nascimento et al., 2001). Another important observation seen during depth profiling measurements of residual stress was that there is no change in preferred crystallographic texture along the thickness of chrome plating. It points to the fact that during chrome plating, grains nucleated from the surface of the substrate grow with preferred orientation which remains unchanged during the deposition of thick chrome plating. Depth measurements of residual stress in chrome plated specimens also brought out that the coating/substrate interface can be detected with (i) significant reduction in peak width and (ii) shift in position of diffracted peak towards lower diffraction angle, as shown in figure. 10. It can be inferred from these results that the anisotropy/crystallographic texture of the surface (electroplated/any other surface) can also diagnosed along with the residual stress data using the X-ray based residual stress measurement system.

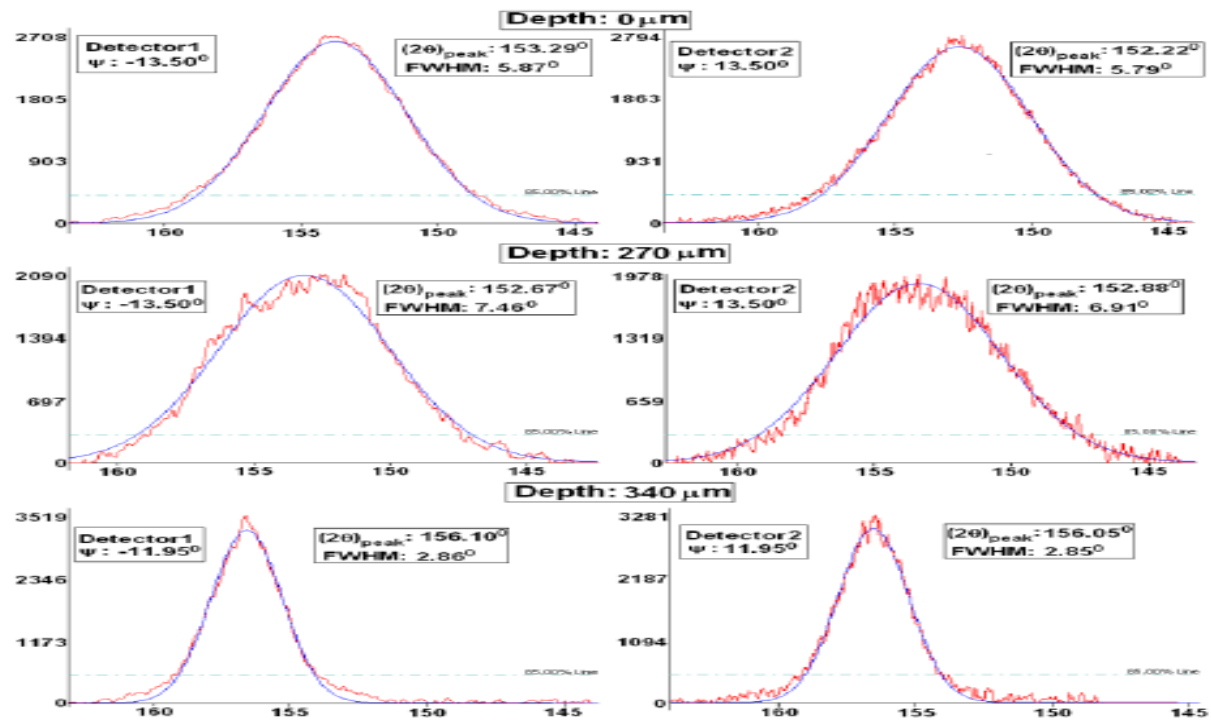

Figure 10. Profiles of $\mathrm{Cr}$ (211) diffraction peak at different depths from the chrome plated surface. Note reduced peak width and shift in diffraction peak in the substrate (15-5 PH SS) in the bottom most profile.

\section{Conclusions}

The results of the case studies, described in this paper, have demonstrated that diffraction peak width and variation of the intensity of the diffraction peak are two important parameters, provided by residual stress analyzer, which can be correlated to micro-structural state of the investigated surface. The mean width of given diffraction peak has been found to be sensitive index to detect (i) surface cold deformation associated with higher FWHM and its subsequent drop due to elimination of cold work effects through surface melting/re-crystallization in austenitic stainless steel and (ii) surface decarburization associated with significant decrease in FWHM of ferrite diffraction peak with respect to bulk. In the case of surface transformation hardening, sharp rise in FWHM appeared to be a more sensitive parameter, than residual stress, to record changes in associated microstructure. On the other hand, variation in the intensity of diffracted peak of 
hard chrome plated surface with respect to various X-ray inclination angles $(\psi)$ provided valuable information regarding strong $\{111\}$ crystallographic texture of the hard chrome plating. The direct implication of these results is that the portable residual stress measurement system can be effectively exploited as an in-situ non-destructive tool to extract useful information regarding surface microstructure of an as-fabricated component or service induced microstructural changes.

\section{Acknowledgment}

Authors thankfully acknowledge technical assistance of Mr. Ram Nihal Ram and Mr. Anil Adbol during the course of this study. Authors are grateful to Dr. Sanjay Rai of ISUD, RRCAT for suggestions and useful technical discussions during the manuscript preparation.

\section{References}

Cullity, B. D. (1978). Elements of X-ray Diffraction ( $2^{\text {nd }}$ ed). Addison-Wesley, Menlo Park, CA.

Deprez, P., Coutouly, J., Crampon, J., \& Deffontains, A. (1990). Surface transformation hardening of steels with $\mathrm{CO}_{2}$ laser. Lasers in Engineering, 8, 105-117.

Dinesh, B. P., Buvanashekaran, G., \& Balasubramanian, K. R. (2013). Experimental investigation of laser transformation hardening of low alloy steel using response surface methodology. The International Journal of Advanced Manufacturing Technology, 67(5-8), 1883-1897. http://dx.doi.org/10.1007/s00170-012-4616-z

Dobmann, G., Meyendorf, N., \& Schneider, E. (1997). Nondestructive characterization of materials a growing demand for describing damage and service-life-relevant aging processes in plant components. Nuclear Engineering and Design, 171(1), 95-112. http://dx.doi.org/10.1016/S0029-5493(96)01319-2

Dubpernell, G., \& Lowenheim, F. A. (1968). Modern Electroplating ( $2^{\text {nd }}$ ed), Lowenheim, F. A., Ed., John Wiley and Sons Inc., New York, 80-140.

Etienne, A., Radiguet, B., Genevois, C., Breton, L., J. M., Valiev, R., \& Pareige, P. (2010). Thermal stability of ultrafine-grained austenitic stainless steels. Materials Science and Engineering: A, 527(21-22), 5805-5810. http://dx.doi.org/10.1016/j.msea.2010.05.049

Frank, H. C., \& Deane, K. S. (Eds.) (2000). Industrial applications of X-ray diffraction. Marcel Dekker AG, New York, USA.

Ganesh, P., Sundar, R., Kumar, H., Kaul, R., Ranganathan, K., Hedaoo, P., Tiwari, P., Kukreja, L. M., Oak, S. M., Dasari, S., Raghavendra, G. (2012). Studies on laser peening of spring steel for automotive applications. Optics and Lasers in Engineering, 50, 678 - 686. http://dx.doi.org/10.1016/j.optlaseng.2011.11.013

Ganesh, P., Kumar, H., Kaul, R., \& Kukreja, L. M. (2013a). Microstructural characterization of laser surface treated AISI 1040 steel with portable X-ray stress analyzer. Surface Engineering, 29, 600-607. http://dx.doi.org/10.1179/1743294413Y.0000000170

Ganesh, P., Vinod, K. A., Thinaharan, C., Nanda, G. K., George, R. P., Parvatahvarthini, N., Rai, S. K., Kaul, R., Mudali, U. K., \& Kukreja, L. M. (2013b). Enhancement of Intergranular corrosion resistance of type 304 stainless steel through a novel surface thermo-mechanical treatment. Surface and Coating Technology, 232, 920-927. http://dx.doi.org/10.1016/j.surfcoat.2013.06.124

Ganesh, P., Sundar, R., Kumar, H., Kaul, R., Ranganathan, K., Hedaoo, P., Raghavendra, G., Anand, K. S., Tiwari, P., Nagpure, D. C., Bindra, K. S., Kukreja, L. M., \& Oak, S. M. (2014). Studies on fatigue life enhancement of pre-fatigued spring steel specimens using laser shock peening. Materials and Design, 54, 734-741. http://dx.doi.org/10.1016/j.matdes.2013.08.104

Ghosh, S., \& Kain, V. (2010). Microstructural changes in AISI 304L stainless steel due to surface machining: Effect on its susceptibility to chloride stress corrosion cracking. Journal of Nuclear Materials, 403(1-3) 62-67. http:// doi:10.1016/j.jnucmat.2010.05.028

Ghosh, S., Rana, V. P. S., Kain, V., Mittal, V., \& Baveja, S. K. (2011). Role of residual stresses induced by industrial fabrication on stress corrosion cracking susceptibility of austenitic stainless steel. Materials \& Design, 32(7), 3823-3831. http:// doi:10.1016/j.matdes.2011.03.012

Gupta, R. K., Sundar, R., Sunil K. B., Ganesh, P., Kaul, R., Ranganathan, K., Bindra, K. S., Kain, V., Oak, S. M., \& Kukreja, L. M. (2015). A hybrid laser surface treatment for refurbishment of stress corrosion cracking damaged 304L stainless steel, Journal of Materials Engineering and Performance, In press.

Hosford, W. F. (2005). Physical Metallurgy, Boca Raton, FL, CRC Press, Taylor and Francis Group, 153-165.

Ion, J. C. (2002). Laser transformation hardening. Surface Engineering, 18, 14-31. 
http://dx.doi.org/10.1179/026708401225001228

Jang, D.Y., Watkins, T, R., Kozaczek, K. J., Hubbard, C. R., \& Cavin, O. B. (1996). Surface residual stresses in machined austenitic stainless steel. Wear, 194, 168-173. http://dx.doi.org/10.1016/0043-1648(95)06838-4

Jones, A. R. (1989). Microcracks in hard chromium electrodeposits. Plating and Surface Finishing, 76, 62-66.

Kaul, R., Ganesh, P., Tiwari, P., Nandedkar, R. V., \& Nath A. K. (2005). Characterization of dry sliding wear resistance of laser surface hardened En8 steel. Journal of Materials Processing Technology, 167, 83-90. http://dx.doi.org/10.1016/j.jmatprotec.2004.09.085

Kaul, R., Mahajan, S., Kain, V., Ganesh, P., Chandra, K., Samajdar, I., Nath A. K., \& Prasad, R. C. (2008). Laser Surface Treatment for Enhancing Intergranular Corrosion Resistance of AISI 304 Stainless Steel, Corrosion, 64, 755-762. doi: http://dx.doi.org/10.5006/1.3278443

Kaul, R., Parvathavarthini, N., Ganesh, P., Mulki, S. V., Samajdar, I., Dayal, R. K., \& Kukreja, L. M. (2009). A Novel Pre-weld Laser Surface Treatment for Enhanced Inter-granular Corrosion Resistance of Austenitic Stainless Steel Weldment. Welding Journal, 88, 233s - 242s.

Kennedy, E., Bryne, G., \& Collins, D. N. (2004). A review of the use of high power diode laser in surface hardening, $\begin{array}{lllll}\text { Journal of Materials } & \text { Processing }\end{array}$ http://dx.doi.org/10.1016/j.jmatprotec.2004.04.276

Koul, A. K., \& Castillo, R. (1988). Assessment of service induced microstructural damage and its rejuvenation in turbine blades. Metallurgical Transactions A, 19(8), 2049-2066. doi: http:// 10.1007/BF02645208

Kuo, H. S., \& Wu, J. K. (1996). Passivation treatment for inhibition of hydrogen absorption in chromium-plated steel. Journal of Materials Science. 31, 6095-6098. doi: 10.1007/BF01152165

Liu, C. S., Cai, Q. K., \& Xu, H. (1992). The Influence of Laser Transformation Hardening on Fatigue Crack Initiation of 40Cr Steel. In Rie, K. T. et al (Eds.), Low Cycle Fatigue and Elasto-Plastic Behaviour of Materials-3, 148-153. Springer, Netherlands. http://dx.doi.org/10.1007/978-94-011-2860-5_24

Mandal, A., Murty, B. S., \& Chakraborty, M. (2009). Wear behaviour of near eutectic Al-Si alloy reinforced with in-situ $\mathrm{TiB}_{2}$ particles, Materials Science and Engineering: A, 506(1-2), 27-33. http://dx.doi.org/10.1016/j.msea.2008.11.007

Mathew, M. D., Palanichamy, P., Latha, S., Jayakumar, T., Bhanu, S. R, K., Mannan, S. L., \& Baldev, R. (2010). Microstructural changes in alloy 625 due to creep and characterization using NDE techniques, Transactions of the Indian Institute of Metals, 63(2-3), 449-452. http://dx.doi.org/10.1007/s12666-010-0062-5

Nanekar, P.P., \& Shah, B. K. (2004). Characterization of material properties by ultrasonics. BARC Newsletter Founder's Day Special Issue, 249, 25-38.

Nascimento, M. P., Souza, R. C., Miguel, I. M., Pigatin W. L., \& Voorwald, H. J. C. (2001). Effects of tungsten carbide thermal spray coating by HP/HVOF and hard chromium electroplating on AISI 4340 high strength steel. Surface and coatings Technology. 138, 113-124. http://dx.doi.org/10.1016/S0257-8972(00)01148-8

Noyan, I. C., \& Cohen, J. B. (1987). Residual Stress, Springer-Verlag, New York. http://dx.doi.org/10.1007/978-1-4613-9570-6

Parvathavarthini, N., Dayal, R. K., Kaul, R., Ganesh, P., Khare, J., Nath, A. K., Mishra, S. K., \& Samajdar, I. (2008). Novel Laser Surface Treatment Approach to Suppress Sensitization in Modified Type 316(N) Stainless Steel Weld Metal. Science and Technology of Welding and Joining, 13(4), 335-343. http://dx.doi.org/10.1179/174329308X299931

Pashby, I. R., Barnes, S., \& Bryden, B. G. (2003). Surface hardening of steel using a high power diode laser, Journal of Materials Processing Technology, 139, 585-588. http://dx.doi.org/10.1016/S0924-0136(03)00509-0

Pina, J., Dias, A., François, M., \& Lebrun, J. L. (1997). Residual Stresses and Crystallographic Texture in Hard-chromium Electroplated Coatings. Surface and coatings Technology, 96, 148-162. http://dx.doi.org/10.1016/S0257-8972(97)00075-3

Rai, S. K., Kumar, A., Shankar, V., Jayakumar, T., Bhanu, S. R. K., Baldev, R. (2004). Characterization of microstructures in Inconel 625 using X-ray diffraction peak broadening and lattice parameter measurements, Scripta materialia, 51(1), 59-63. http://dx.doi.org/10.1016/j.scriptamat.2004.03.017

Rai, S. K., Choudhary, B. K., Jayakumar, T., Rao, K., \& Baldev, R. (1999). Characterization of low cycle fatigue damage in $9 \mathrm{Cr}-1 \mathrm{Mo}$ ferritic steel using X-ray diffraction technique, International journal of pressure vessels and piping. 76(5) 275-281. http://dx.doi.org/10.1016/S0308-0161(98)00140-9 
Reed-Hill, R. E. (1973). Physical Metallurgy (2nd Ed.). New Delhi, Affiliated East-West Press Pvt. Ltd., 720-729.

Sagar, S., Palit., R., Kumar, B., Dobmann, G., \& Bhattacharya, D. K., (2005). Magnetic characterization of cold rolled and aged AISI 304 stainless steel. NDT\&E International, 38(8), 674-681. http://dx.doi.org/10.1016/j.ndteint.2005.04.004

Snyder, J. F., Hans, J. B., \& Robert, L. (Eds.) (1999). Defect and microstructure analysis by diffraction, International union of crystallography. Oxford University press Inc., New York USA.

Subba, R., R. V., Parvathavarthini, N., Pujar, M. G., Dayal, R. K., Khatak, H. S., Kaul, R., Ganesh, P., \& Nath, A. K. (2007). A Improved Pitting Corrosion Resistance of Cold Worked and Thermally Aged AISI Type 316L(N) SS by Laser Surface Modification. Surface Engineering, 23, 83-92. http://dx.doi.org/10.1179/174329407X169412

Vivek, R., Binayaka, N., Mohd, Z. K. Y., \& Meghanshu Vashista, (2013). Assessment of Plastic Deformation Upon Grinding Using X-Ray Diffraction Profiles. International Journal of Engineering Research, 2(2), 119-124. www.ijer.in/ijer/publication/v2s2/paper20.pdf

Yamashita, M., Viswananathan, U. K., Yamamoto, I., \& Toshiro, K. (1997). Service-induced Changes in the Microstructure and mechanical Properties of a Cr-Mo-Ni-V Turbine Steel. ISIJ International, 37(11), 1133-1138. http:// doi: $10.2355 /$ isijinternational.37.1133

\section{$(\mathrm{cc})$ EY}

This work is licensed under a Creative Commons Attribution 3.0 License. 